Article

\title{
Hybrid Mesoporous Silica Nanoparticles Grafted with 2-(tert-butylamino)ethyl Methacrylate-b-poly(ethylene Glycol) Methyl Ether Methacrylate Diblock Brushes as Drug Nanocarrier
}

\author{
Abdullah M Alswieleh ${ }^{1, *,+}$, Abeer M Beagan ${ }^{1,+}$, Bayan M Alsheheri ${ }^{1}$, Khalid M Alotaibi ${ }^{1}$, \\ Mansour D Alharthi ${ }^{1}$ and Mohammed S Almeataq ${ }^{2, *}$ \\ 1 Department of Chemistry, College of Science, King Saud University, Riyadh 11451, Saudi Arabia; \\ beagan@ksu.edu.sa (A.M.B.); Bys9314@gmail.com (B.M.A.); khalid.m@ksu.edu.sa (K.M.A.); \\ manalharthi@ksu.edu.sa (M.D.A.) \\ 2 King Abdulaziz City for Science and Techenology, Riyadh 11451, Saudi Arabia \\ * Correspondence: aswieleh@ksu.edu.sa (A.M.A.); mmeataq@kacst.edu.sa (M.S.A.) \\ + These authors contributed equally to this work.
}

Received: 29 November 2019; Accepted: 30 December 2019; Published: 3 January 2020

\begin{abstract}
This paper introduces the synthesis of well-defined 2-(tert-butylamino)ethyl methacrylate-b-poly(ethylene glycol) methyl ether methacrylate diblock copolymer, which has been grafted onto mesoporous silica nanoparticles (PTBAEMA-b-PEGMEMA-MSNs) via atom transfer radical polymerization (ATRP). The ATRP initiators were first attached to the MSN surfaces, followed by the ATRP of 2-(tert-butylamino)ethyl methacrylate (PTBAEMA). CuBr2/bipy and ascorbic acid were employed as the catalyst and reducing agent, respectively, to grow a second polymer, poly(ethylene glycol) methyl ether methacrylate (PEGMEMA). The surface structures of these fabricated nanomaterials were then analyzed using Fourier Transform Infrared (FTIR) spectroscopy. The results of Thermogravimetric Analysis (TGA) show that ATRP could provide a high surface grafting density for polymers. Dynamic Light Scattering (DLS) was conducted to investigate the $\mathrm{pH}$-responsive behavior of the diblock copolymer chains on the nanoparticle surface. In addition, multifunctional pH-sensitive PTBAEMA-b-PEGMEMA-MSNs were loaded with doxycycline (Doxy) to study their capacities and long-circulation time.
\end{abstract}

Keywords: mesoporous silica nanoparticles; polymer brushes; $\mathrm{pH}$ responsive polymer; surface-initiated atom transfer radical polymerization

\section{Introduction}

Mesoporous silica nanoparticles (MSNs) have been studied extensively and applied in various areas, such as colloid chemistry, catalysis, photonics, biosensing, and drug delivery. The great potential of these materials can be attributed to their high rigidity and thermal stability as well as large surface areas, large pore volumes, excellent physicochemical stabilities, and ease of modification [1-5]. MSNs are usually modified on the surface with organic materials, especially polymers, to form silica polymer core/shell nanohybrids [4-8]. Polymer-grafted MSNs combine the advantages of MSNs and organic film to increase the potential applications of these nanomaterials, especially in controlled drug delivery [9-13].

However, controlling the release of a drug from a nanocarrier faces unique challenges, which normally depend on the nanoparticle's characteristics. Therefore, in order to design a nanosystem with the drug-release kinetics desired for the target applications, it is important to understand the 
drug-releasing mechanisms [14]. In the past few years, the concept of stimuli-responsive drug delivery systems (i.e., temperature-responsive, light-responsive, enzyme-responsive, or $\mathrm{pH}$-responsive systems) has been developed for tailoring the release profiles $[7,15]$.

Various methods have been used to synthesize silica polymer core/shell hybrid nanoparticles, including surface-initiated reversible addition-fragmentation chain transfer polymerization (RAFT), surface-initiated nitroxide-mediated polymerization (NMP) and surface-initiated atom transfer radical polymerization (SI-ATRP) [16-19]. SI-ATRP have been used to grow a densely anchored polymer shell with a high degree of control in terms of the size, structure, and uniformity of the polymer chains (polymer brushes) [20,21].

Depending on the chemical composition, a change in the conformation of the polymer chains can be achieved when an external stimuli is applied, such as temperature [22-24], solvents [24-26], and $\mathrm{pH}$ [24,27-29]. The synthesis of poly( $\mathrm{N}$-isopropyl-acrylamide-cohydroxymethyl acrylamide)-shell-MSNs was reported by Liu et al. [10]. Their results showed that the drug release rate was dependent on the temperature. Liu and co-workers reported the synthesis of hybrid silica nanoparticles grafted onto thermo-responsive poly(ethylene glycol) methyl ether methacrylate (PEGMEMA) which possessed the ability to undergo emulsification-demulsification inversion in response to temperature [30]. An intelligent drug delivery system based on MSNs coated with an ultra-pH-sensitive polymer and poly(ethylene glycol) was synthesized by Chen et al. [31]. The DOX-drug release behavior was reported to be $\mathrm{pH}$ dependent with good control. Alswieleh et al. reported the growth of a secondary amine, poly(2-(tert-butylamino)ethyl methacrylate) (PTBAEMA), using SI-ATRP and studied the $\mathrm{pH}$-responsive behavior of these linear brushes [32].

Attention has also been paid to dual stimuli-responsive polymers, which is promising area for smart nanodevices. Further, Chang et al. synthesized $\mathrm{pH}$ and thermo dual-responsive poly(N-isopropylacrylamide-co-methacrylic acid) core/shell nanohybrids for controlled drug release [33]. Finally, $\mathrm{Wu}$ et al. reported the synthesis of hybrid silica nanoparticles with well-defined thermo and $\mathrm{pH}$ dual-responsive poly( $\mathrm{N}$-isopropylacrylamide)-b-poly(4-vinylpyridine) (SNPs-g-PNIPAM-b-P4VP) via SI-ATRP [34].

To the best of our knowledge, very little work has been done on the synthesis of diblock polymers grafted onto nanoparticles. However, as far as we are aware, no work has been done on fabricating mesoporous silica materials with $\mathrm{pH}$ and thermo dual-responsive diblock brushes, as well as a drug nanocarrier. In this study, we have synthesized a PTBAEMA-b-PEGMEMA diblock copolymer grafted onto mesoporous silica nanoparticles (MSNs) via surface-initiated ATRP/ARGET ATRP methods. First, the MSNs were synthesized with amine groups along the inner surface and with pore sizes of $\sim 6.0 \mathrm{~nm}$. Thereafter, PTBAEM was grown on the ATRP initiator-attached mesoporous silica nanoparticle outer surface via SI-ATRP. The PTBAEM end groups can be reinitiated to continue the polymerization on an MSN's surface with a second monomer, which leads to grafting diblock copolymers onto its surface. The AGET ATRP method allows precise control of the polymer length, thus, it was used to grow a second polymer, namely, PEGMEMA. The pH-responsiveness of the diblock copolymer chains on an MSN's surface can be studied via Dynamic Light Scattering (DLS).

\section{Materials and Methods}

\subsection{Materials}

An Elga Pure Nanopore 18.2 $\mathrm{M} \Omega$ system was used to obtain deionized water. Tetraethylorthosilicate (TEOS, 98\%), $N$-cetyltrimethylammonium bromide (CTAB, 98\%), ammonium hydroxide (28 wt. \%), 3-aminopropyltriethoxysilane (APTES, >98\%), 2-bromoisobutyryl bromide (BIBB, 98\%), triethylamine (TEA, 99\%), 2-(tert-butylamino)ethyl methacrylate (TBAEMA, 97\%), poly(ethylene glycol) methyl ether methacrylate (PEGMEMA, average Mn 500), copper(I) chloride ( $>98 \%)$, copper(II) bromide (>99\%), 2,2' bipyridine (>99\%), methanol (99.8\% HPLC grade), ethanol (99.8\%, HPLC grade), isopropyl alcohol (analytical grade), toluene (analytical grade), and dichloromethane (DCM, HPLC 
grade) were purchased from Sigma-Aldrich (Steinheim, Germany). Hydrochloric acid ( $\mathrm{HCl}$ ) was obtained from Fisher Scientific (Loughborough, UK). All the chemicals were used as received. TBAEMA and PEGMEMA were treated with basic alumina to remove the inhibitor and stored at $5{ }^{\circ} \mathrm{C}$ before use.

\subsection{Synthesis of Mesoporous Silica Nanoparticles (without Amine in the Pores)}

First, $1.0 \mathrm{~g}$ of CTAB was dissolved in $160 \mathrm{~mL}$ of deionized water under stirring for $10 \mathrm{~min}$. Concentrated ammonia water $(7.0 \mathrm{~mL}, 28 \mathrm{wt}$. \%) was added to the solution. After that, a mixture solution of n-hexane $(20 \mathrm{~mL})$, and TEOS $(5 \mathrm{~mL})$ were added to the solution within 20 min under stirring at $35{ }^{\circ} \mathrm{C}$. After stirring for $15 \mathrm{~h}$, the product was collected by centrifugation and washed with deionized water and ethanol.

\subsection{Synthesis of Mesoporous Silica Nanoparticles (with Amine in the Pores)}

Here, $1.0 \mathrm{~g}$ of CTAB was dissolved in $160 \mathrm{~mL}$ of deionized water under stirring for $10 \mathrm{~min}$. Concentrated ammonia water $(7.0 \mathrm{~mL}, 28 \mathrm{wt}$. \%) was added to the solution. After that, a mixture solution of n-hexane $(20 \mathrm{~mL})$, APTES $(0.2 \mathrm{~mL}, 1 \mathrm{mmol})$, and TEOS $(5 \mathrm{~mL})$ were added to the solution within $20 \mathrm{~min}$ under stirring at $35^{\circ} \mathrm{C}$. After stirring for $15 \mathrm{~h}$, the product was collected by centrifugation and washed with deionized water and ethanol.

\subsection{Synthesis of 3-Aminopropyl-Functionalized MSNs (AP-MSNs)}

Mesoporous silica nanoparticles (1.5 g) were suspended in a solution of APTES (0.6 mL, $2.5 \mathrm{mmol})$ in dry toluene $(50.0 \mathrm{~mL})$ and heated overnight under reflux. The nanoparticles were then collected by centrifugation, washed twice with toluene and five times with ethanol, and dried under vacuum.

\subsection{ATRP Initiator Attached on MSNs Outer Surface (BiBB-MSNs)}

In a $100 \mathrm{~mL}$ flask, AP-MSNs $(1.0 \mathrm{~g}), \mathrm{DCM}(40.0 \mathrm{~mL})$, and triethylamine $(1.5 \mathrm{~mL}, 11 \mathrm{mmol})$ were mixed, then BIBB $(1.2 \mathrm{~mL}, 10 \mathrm{mmol})$ in $5 \mathrm{~mL}$ of DCM was added dropwise to the mixture. The mixture was stirred overnight at room temperature. The modified nanoparticles were centrifuged, washed three times with DCM and five times with ethanol, and dried under vacuum.

\subsection{Formation of BiBB-MSNs Nanochannels}

BiBB-MSNs were treated with a solvent extraction to remove surfactant by adding $1.5 \mathrm{~g}$ of BIBB-MSNs to a solution of ammonium nitrate $(10 \mathrm{mg} / \mathrm{mL})$ in ethanol $(95 \%)$ at $80{ }^{\circ} \mathrm{C}$, then having this mixture undergo magnetic stirring overnight. The sample was collected by centrifugation, followed with washing with ethanol three times, and vacuum dried overnight.

\subsection{PTBAEMA Brushes Grafted on MSNs Surface}

BiBB-MSNs (200 mg) were dispersed in a mixture of isopropanol (IPA, $4 \mathrm{~mL}$ ), water (1 mL), and TBAEMA ( $2.7 \mathrm{~g}, 15 \mathrm{mmol})$ at room temperature, then deoxygenated for $30 \mathrm{~min}$. $\mathrm{Cu}(\mathrm{II}) \mathrm{Br}_{2}(2.2 \mathrm{mg}$, $0.01 \mathrm{mmol})$ and bipy $(30.0 \mathrm{mg}, 0.2 \mathrm{mmol})$ were added to the mixture, which was deoxygenated for 10 min. Copper $(\mathrm{I})$ chloride $(\mathrm{CuCl})(2.0 \mathrm{mg}, 0.02 \mathrm{mmol})$ was then added to the mixture. The polymerization reaction was allowed to proceed under a nitrogen atmosphere for $3 \mathrm{~h}$. Then the final product was washed with IPA and ethanol and dried under vacuum.

\subsection{Copolymer Brushes Grafted on MSNs Surface via AGET-ATRP}

PTBAEMA-MSNs (1.50 g) was dispersed in $10 \mathrm{~mL}$ of $\mathrm{CH} 2 \mathrm{Cl} 2, \mathrm{CuBr} 2(0.1671 \mathrm{~g})$ and bipy (0.702 g) were added, then the mixture was stirred at room temperature. PEGMEMA $(1.5 \mathrm{~g})$ and $30 \mathrm{~mL}$ of deionized water were added to the mixture at room temperature. The reaction mixture was purged with nitrogen for $30 \mathrm{~min}$ to evaporate $\mathrm{CH}_{2} \mathrm{Cl}_{2}$. Ascorbic acid (0.04 mmol) was added dropwise into the 
deoxygenated solution at $70^{\circ} \mathrm{C}$. PTBAEMA-b-PEGMEMA-MSNs were recovered by centrifugation, washed with ethanol several times, and dried under vacuum.

\subsection{Doxycycline (Doxy) Loading and pH-Triggered Release}

PTBAEMA-b-PEGMEMA-MSNs were dispersed in DI water (1 mg/mL). Next, Doxy $(0.4 \mathrm{mg}$ Doxy per mg of fabricated nanoparticles) was added to the suspension, and the $\mathrm{pH}$ of the resulting mixture was adjusted to 3.0 with $\mathrm{HCl}(1 \mathrm{M})$ aqueous solution. The suspension was stirred overnight at room temperature. Thereafter, the $\mathrm{pH}$ of the mixture was adjusted to 9.0, and it was stirred for $2 \mathrm{~h}$. Subsequently, the Doxy-loaded PTBAEM-b-POEGMA-MSNs were centrifuged and washed twice with a dilute solution of $\mathrm{NaOH}(\mathrm{pH}=9.0)$ to remove the surface adsorbed Doxy. The unloaded Doxy was determined to be in the supernatant based on a standard calibration curve for Doxy.

The encapsulation efficiency (EE) was determined according to the following equation:

$$
\mathrm{EE}(\%)=(\text { Weight of loaded drug/Weight of drug in feed }) \times 100 \% \text {, }
$$

Doxy-loaded PTBAEMA-b-POEGMA-MSNs were suspended in $(\mathrm{pH}=6, \mathrm{pH}=7, \mathrm{pH}=8$, and $\mathrm{pH}=9$ ) solution at a concentration equal to $0.25 \mathrm{mg}$ NPs/mL. At specific time points, the fabricated nanoparticles were centrifuged and an aliquot of the supernatant $(1 \mathrm{~mL})$ was removed and replaced with an equal volume. The amount of Doxy released in the supernatant was calculated based on the calibration curve of Doxy in the same buffer.

\subsection{Measurement and Characterization}

FTIR Spectroscopy: Infrared spectra of all fabricated nanoparticles were obtained in KBr pellets in the $4000-400 \mathrm{~cm}^{-1}$ region with a resolution of $4 \mathrm{~cm}^{-1}$, using a Thermo Scientific Nicolet iS10. Elemental Analysis (EA): EA was carried out using a Perkin Elmer Series II-2400 analyzer. Scanning Electron Microscopy (SEM): SEM images were obtained using JEOL JSM-6380 LA. The samples were used for the observation without any treatment. Transmission Electron Microscopy (TEM): A drop of dilute sample suspension in ethanol was placed on a copper grid and dried at room temperature. A JEOL JEM-1230 transmission electron microscope was used to collect TEM imaging. Thermogravimetric Analysis (TGA): TGA analyses were carried out on a SII TGA 6300 instrument with $10^{\circ} \mathrm{C} / \mathrm{min}$ heating rate under $\mathrm{N}_{2}$. Dynamic light scattering (DLS) measurements were collected using Zetasizer nano ZS (Malvern Instruments, Malvern, UK) at $25^{\circ} \mathrm{C}$. UV spectra were recorded on Shimadzu (UV-2600) UV-VIS spectrophotometer.

\section{Results and Discussion}

MSNs were synthesized by allowing TEOS to react with a template made of micellar rods (CTAB) in the presence of a pore expander (n-hexane) and APTES in order to functionalize the internal mesopore surface. PTBAEMA-b-PEGMEMA copolymer brushes on MSNs were prepared according to Scheme 1. Due to the hydroxyl groups on the external surface, APTES can be conveniently attached onto the MSNs surface to functionalize the particles with initiator units. The MSNs-Br was obtained via the reaction of the amino groups in $\mathrm{MSNs}-\mathrm{NH}_{2}$ with 2-bromo-2-methylpropionyl bromide (BIBB) before removing $\mathrm{CTAB}$ to avoid reactions in the internal surfaces of the pores. The surfactant was removed using an acidic solution in methanol at $80^{\circ} \mathrm{C}$. SI-ATRP method was used to grow PTBAEMA brushes, followed by the growth of PEGMEMA on MSNs' external surfaces via AGET-ATRP, to obtain PTBAEMA-b-PEGMEMA-MSNs. 


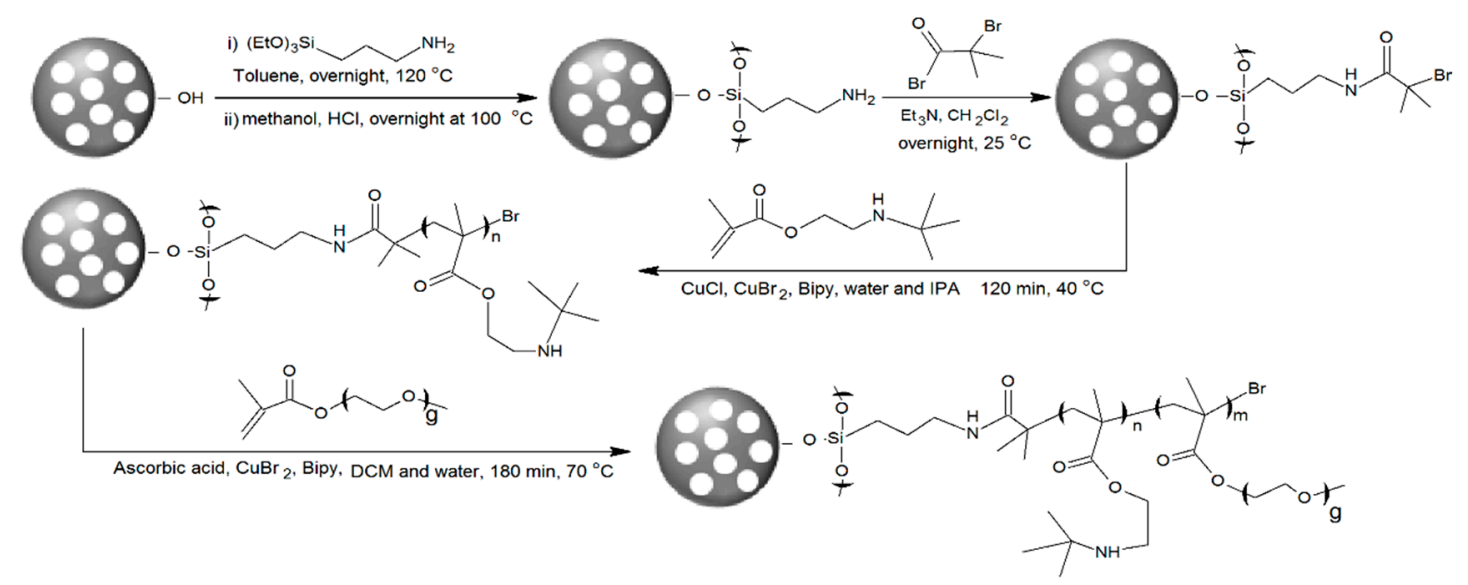

Scheme 1. Synthesis procedure for 2-(tert-butylamino)ethyl methacrylate-b-poly(ethylene glycol) methyl ether methacrylate diblock copolymer (PTBAEMA-b-PEGMEMA) copolymer brushes on mesoporous silica nanoparticle (MSN) surfaces via SI/SI-ARGET ATRP.

The sizes, shapes, and distribution of the colloidal fabricated nanoparticles were observed using scanning electron microscopy (SEM) and transmission electron microscopy (TEM). SEM images of unmodified MSNs and PTBAEMA-b-PEGMEMA attached MSNs are shown in Figure 1. The image shows that the as-made MSN sample contains nearly nanospherical particles. The as-made MSNs exhibited an average size of $180 \mathrm{~nm}$, as shown in Figure 1A. The SEM image suggest that the particles are coated with a polymer shell which is not visible for the unmodified particles and Zhiping Du made a similar observation (Figure 1B) [30].
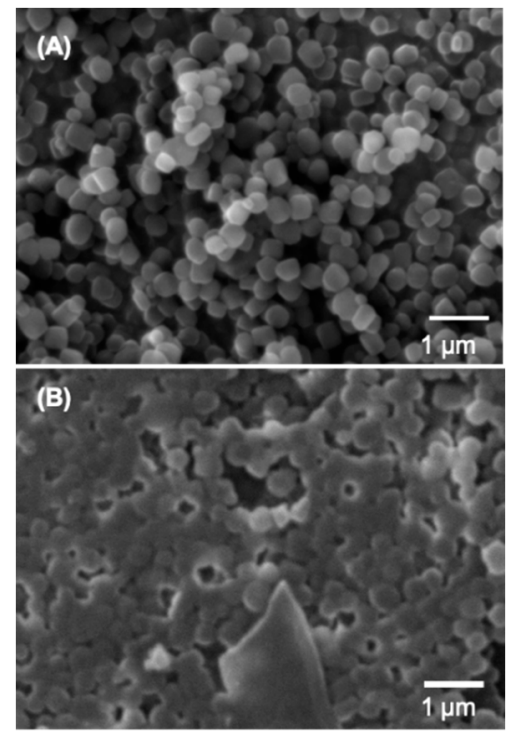

Figure 1. SEM images of fabricated mesoporous silica nanoparticles. (A) SEM image of unmodified MSNs. (B) SEM image of PTBAEMA-b-PEGMEMA attached to MSNs.

TEM images of bare MSNs and PTBAEMA-b-PEGMEMA attached to MSN composites are illustrated in Figure 2. Figure 2A shows that the unmodified nanoparticles are dispersed and have an almost regular morphology with average diameters $170 \mathrm{~nm}$, which is in good agreement with the SEM image (Figure S1 in Supplementary Materials). The mesoporous size was estimated to be approximately $6 \mathrm{~nm}$ from the TEM image, which is larger than those of typical mesoporous silica nanoparticles due to the effect of $n$-hexane. In Figure 2B, the observed diameters of PTBAEMA-b-PEGMEMA attached MSNs are larger, and clear core/shell structures due to the polymer chains that are anchored to the MSNs' external surfaces. 

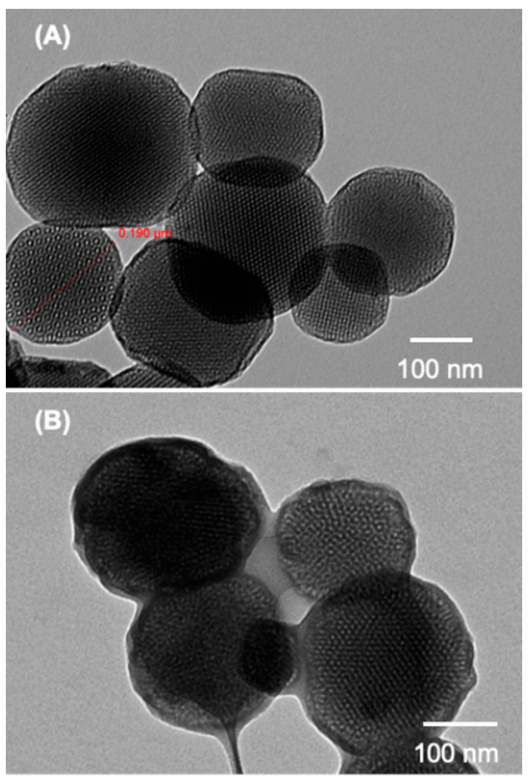

Figure 2. TEM images of fabricated mesoporous silica nanoparticles. (A) TEM image of MSNs, as prepared. (B) TEM image of PTBAEMA-b-PEGMEMA anchored MSNs.

The FTIR spectra were obtained for MSNs-Br, PTBAEMA-MSNs, and PTBAEMA-b-PEGMEMA-MSNs in order to verify that molecules were successfully attached to the surface, see Figure 3. A wide band at $1240-1030 \mathrm{~cm}^{-1}$ was observed, which was attributed to $\mathrm{Si}-\mathrm{O}-\mathrm{Si}$ bands stretching the condensed silica network. Further, there was a peak at $\sim 810 \mathrm{~cm}^{-1}$ caused by the stretching vibration of $\mathrm{Si}-\mathrm{O}$. After linkage of the initiator groups, peaks at $\sim 695 \mathrm{~cm}^{-1}$, $\sim 1490 \mathrm{~cm}^{-1}, \sim 1610 \mathrm{~cm}^{-1}$, and $\sim 1565 \mathrm{~cm}^{-1}$ were assigned to the APTES functionalization, and a doublet in the vicinity of $\sim 1380 \mathrm{~cm}^{-1}$ was due to the isopropyl methyl groups in 2-bromoisobutyrate. The peak at $2930 \mathrm{~cm}^{-1}$ was ascribed to $\mathrm{C}-\mathrm{H}$ as a $-\mathrm{CH}_{2}-$ stretching vibration after the attachment of PTBAEMA to the MSN surfaces, and the absorption band at $\sim 1730 \mathrm{~cm}^{-1}$ belongs to $-\mathrm{C}=\mathrm{O}$ stretching. PTBAEMA-b-PEGMEMA-MSNs FTIR spectra are similar to those for MSN-PTAEBMA. However, there is an increase in the peak intensity at $\sim 1730 \mathrm{~cm}^{-1}$ as a result of increasing the amount of the ( $-\mathrm{C}=\mathrm{O}$ stretching) functional group present, indicating the successful attachment of PEGMEMA to form diblock polymers.

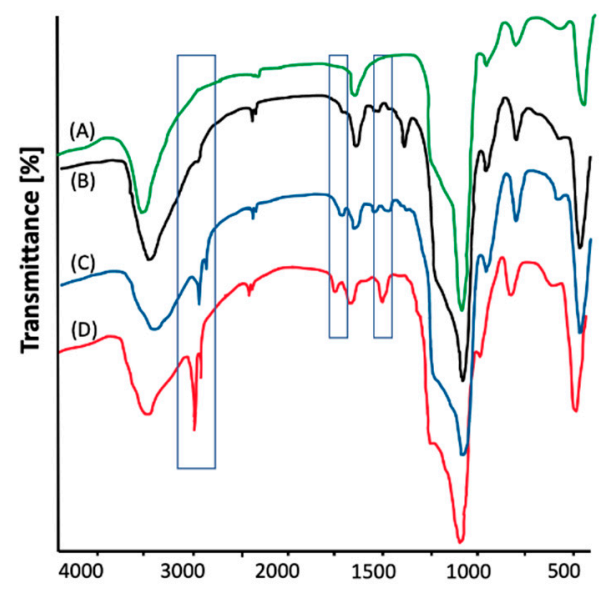

Figure 3. FTIR spectra of (A) unmodified MSNs, (B) MSNs-Br, (C) PTBAEMA-MSNs, and (D) PTBAEMA-b-PEGMEMA-MSNs. 
Elemental analysis was utilized to estimate the number of molecules attached to the surfaces of the MSNs-Br, MSNs-PTEABMA, and PTBAEMA-b-PEGMEMA-MSNs using the measured percentages of carbon, hydrogen, and nitrogen (Table 1). The results clearly show an increase in the percentage of $\mathrm{N}, \mathrm{C}$, and $\mathrm{H}$ elements on the MSNs-Br (with amine in the inner surface) compared to MSNs-Br (without amine in the inner surface), which confirms the presence of the amino group inside the pores. Furthermore, there was a further increase in the amount of $\mathrm{N}, \mathrm{C}$, and $\mathrm{H}$ elements when the diblock copolymer was introduced to the surface of the MSNs over the amounts present in the plain MSNs-Br. The ratio of nitrogen content to carbon in PTBAEMA-MSNs was approximately 19\%, while it was $14 \%$ for PTBAEMA-b-POEGMA-MSNs, further confirming the successful incorporation of the POEGMA into the PTBAEMA-MSNs.

Table 1. Elemental analysis data obtained for the fabricated mesoporous silica nanoparticles.

\begin{tabular}{cccc}
\hline Sample ID & $\mathbf{N} \%$ & $\mathbf{C} \%$ & $\mathbf{H} \%$ \\
\hline MSNs-Br (without amine in inner surface) & 1.92 & 7.85 & 2.12 \\
MSNs-Br (with amine in inner surface) & 2.23 & 7.96 & 2.04 \\
PTBAEMA-MSNs (without amine in inner surface) & 4.08 & 21.73 & 4.07 \\
PTBAEMA-MSNs (with amine in inner surface) & 4.27 & 22.21 & 4.18 \\
PTBAEMA-b-POEGMA-MSNs (without amine in inner surface) & 3.73 & 25.89 & 5.12 \\
PTBAEMA-b-POEGMA-MSNs (with amine in inner surface) & 3.81 & 26.48 & 5.39 \\
\hline
\end{tabular}

Thermogravimetric analysis (TGA)was utilized to evaluate the successful surface modification of MSNs. TGA was performed under nitrogen atmosphere with heating rate of $10{ }^{\circ} \mathrm{C} \mathrm{min}{ }^{-1}$ up to $800{ }^{\circ} \mathrm{C}$, as shown in Figure 4 . The TGA results indicated that the weight loss was approximately $45 \%$ at $\sim 400^{\circ} \mathrm{C}$ for as-made MSNs (CTAB and APTES (inner surface)). After CTAB extraction, the weight retention was ca. $8 \%$ and $\sim 18 \%$ for both $\mathrm{MSNs}-\mathrm{NH}_{2}$ (inner) and MSNs-Br. The result showed that the APTES content in the internal surfaces of MSNs was ca. $0.13 \mathrm{mmol} / \mathrm{g}$, and the initiator on the external surface was ca. $0.05 \mathrm{mmol} / \mathrm{g}$. TGA revealed that the mass retention of PTBAEMA-MSNs was ca. $40 \%$ at $\sim 500{ }^{\circ} \mathrm{C}$. The content of the monomer attached to the outer surface was estimated to be ca. $0.22 \mathrm{mmol} / \mathrm{g}$. The weight loss was ca. $20 \%$ at $\sim 550{ }^{\circ} \mathrm{C}$ for PTBAEMA-b-PEGMEMA-MSNs samples, which suggests that the amount of PEGMEMA grown on the surface is ca. $0.04 \mathrm{mmol} / \mathrm{g}$. Despite the fact that the estimated polymer layer on the surface of the MSNs was only $15 \%$ of the total size of the particles, the polymer weight is considered to be $40 \%$ of the total weight of the nanoparticles These results indicate the possibility of a high surface grafting density for the polymers.

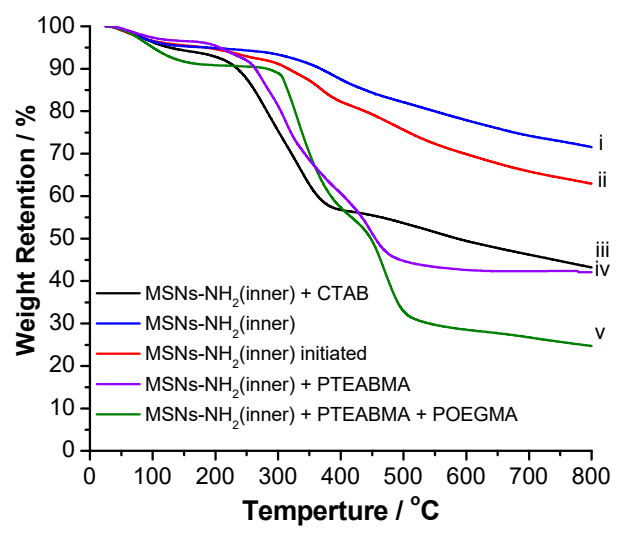

Figure 4. Thermogravimetric analysis (TGA) of the fabricated mesoporous silica nanoparticles. (i) $\mathrm{MSNs}_{2} \mathrm{NH}_{2}$ (amine in inner surface), (ii) MSNs-Br (amine in inner surface), (iii) $\mathrm{MSNs}-\mathrm{NH}_{2}$ (amine in inner surface) and CTAB, (iv) PTBAEMA-MSNs (amine in inner surface), and (v) PTBAEMA-b-PEGMEMA-MSNs (amine in inner surface). 
The $\mathrm{pH}$-responsive behavior of PTBAEMA-MSNs and PTBAEMA-b-PEGMEMA-MSNs was investigated. The average hydrodynamic diameter $(\mathrm{Dh})$ was measured using dynamic light scattering (DLS) at different $\mathrm{pH}$ values ranging from $\mathrm{pH} 2$ to 10, as shown in Figure 5. At $\mathrm{pH}<8$, the PTBAEM chains are protonated and reach maximum swelling at approximately $1000 \mathrm{~nm}$ in thickness (see black dataset in Figure 5). The hydration layer arises on the PTBAEMA-MSNs' outer surfaces, which results in larger particle diameter measurements. The particles collapsed at a $\mathrm{pH}$ of 8 to a diameter of ca. $200 \mathrm{~nm}$ due to the deprotonation process. At $\mathrm{pH}>8$, PTBAEMA-MSNs' diameters were found to be similar to the diameters estimated by TEM due to hydrophobic PTEABMA chains in this media. The PTBAEMA-b-PEGMEMA-MSNs exhibited $\mathrm{pH}$ responsive behavior similar to that of the PTBAEMA-MSNs. It is clear that there was little difference between PTBAEMA-MSNs, and PTBAEMA-b-PEGMEMA-MSNs at $\mathrm{pH}<8$. When the particles were suspended in a solution with $\mathrm{pH}>8$, the diblock brushes exhibited a relatively larger particle size of approximately $350 \mathrm{~nm}$ (red datasets in Figure 5) due to the neutral hydrophilic PEGMEMA polymer. The changes in the average hydrodynamic diameters of PTBAEMA-MSNs and PTBAEMA-b-PEGMEMA-MSNs at different $\mathrm{pH}$ values showed a pKa around 7.7, which is in agreement with the literature [32].

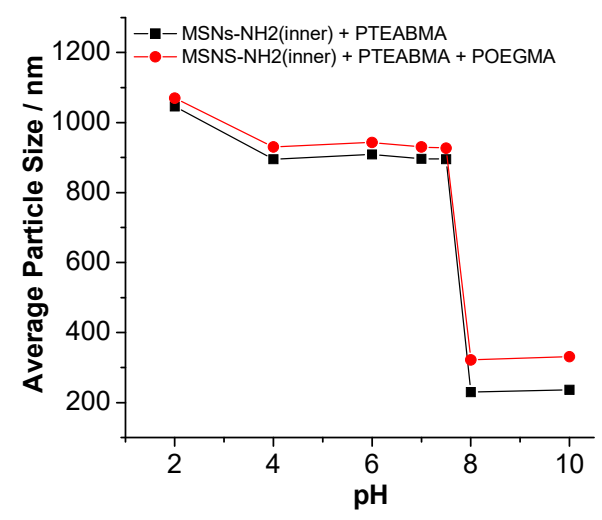

Figure 5. Average hydrodynamic diameters of PTBAEMA-MSNs and PTBAEMA-b-PEGMEMA-MSNs at different $\mathrm{pH}$ values, as measured by dynamic light scattering.

The encapsulation and release of Doxy were investigated as drug delivery vectors for PTBAEMA-b-POEGMA-MSNs (without amine in inner surface) and PTBAEMA-b-POEGMA-MSNs (with amine in inner surface). Doxy was encapsulated in these different MSN samples at an acidic $\mathrm{pH}$ of 4. Under these acidic conditions, the PTBAEMA brushes were stretched and in an opened state due to their protonation. Therefore, the Doxy were able to diffuse into the pores of the nanocarriers. The PTBAEMA chains became deprotonated and collapsed on the MSN surfaces upon adjusting the $\mathrm{pH}$ to 9.0, forming hydrophobic shells to block the drug inside the channels and allowing Doxy to interact with the inner surfaces of the MSNs (Scheme 2). The encapsulation efficiencies of PTBAEMA-b-POEGMA-MSNs (without amine in inner surface) and PTBAEMA-b-POEGMA-MSNs (with amine in inner surface) were calculated to be $38 \%$ and $44 \%$, respectively. The enhanced encapsulation efficiency of PTBAEMA-b-POEGMA-MSNs (with amine in inner surface) compared to PTBAEMA-b-POEGMA-MSNs (without amine in inner surface) indicates that Doxy could be covalently bounded to the interior surfaces of MSNs via amine groups. 
(A)
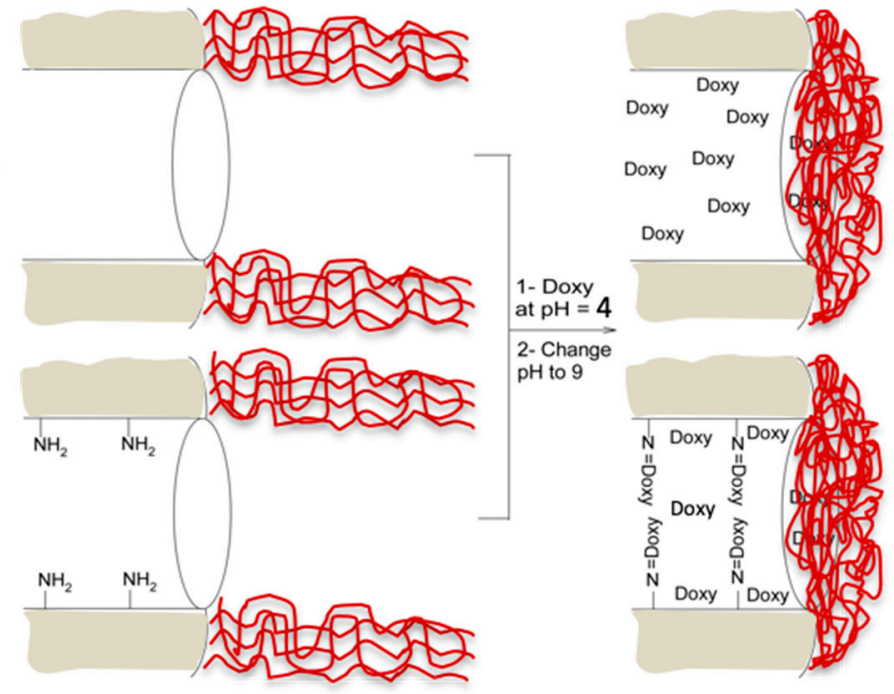

Scheme 2. Schematic illustration of doxycycline (Doxy)-loaded PTBAEMA-b-PEGMEMAfunctionalized MSNs for $\mathrm{pH}$-trigger-controlled drug release. (A) PTBAEMA-b-POEGMA-MSNs (without amine in inner surface) and (B) PTBAEMA-b-POEGMA-MSNs (with amine in inner surface) nanocarriers.

Doxy is a tetracycline antibiotic that treats serious bacterial infections, such as cholera, typhus, and syphilis. The pH-triggered Doxy release profile of the PTBAEMA-b-POEGMA-MSNs was investigated in mild acidic (6.0), neutral (7.0), and basic (8.0 and 9.0) $\mathrm{pH}$ conditions at room temperature (Figure 6). The unmodified inner surfaces of PTBAEMA-b-POEGMA-grafted MSN samples present clear $\mathrm{pH}$-triggered drug release behavior (Figure $6 \mathrm{~A}$ ). In basic media, an $\sim 20 \%$ release was observed after an incubation of $72 \mathrm{~h}$. The drug release was significantly higher at $\mathrm{pH} 6$ and 7 at up to ca. $40 \%$. The acute protonation of PTBAEMA brushes resulted in an open state, facilitating the release of Doxy entrapped by the polymeric shell. The incomplete Doxy release may be ascribed to the physical adsorption of the drug in the inner surfaces of the samples. The release profile for the amino-modified inner surface of PTBAEMA-b-POEGMA-MSNs was investigated in basic media ( $\mathrm{pH} 8$ and 9), exhibiting a constant release of ca. 17\% after a 72-h incubation period (Figure 6B). Upon decreasing the $\mathrm{pH}$ to 6 and 7 , the release of Doxy was greater and reached almost $30 \%$ after a $72-h$ incubation period. The observed release behavior is attributed to the attractive and repelling forces between the amino-modified inner surfaces of the PTBAEMA-b-POEGMA-MSNs and Doxy. Overall, the data shows that the release profiles of Doxy loaded in PTBAEMA-b-POEGMA-MSNs with amine in the inner surface followed release kinetics similar to those of PTBAEMA-b-POEGMA-MSNs without amine in the inner surface at both $\mathrm{pH} 8$ and $\mathrm{pH} 9$ with a drug release of $\sim 20 \%$. The lower release level may indicate the blockage of MSN pores by PTBAEMA-b-POEGMA or possibly the strong interaction between the Doxy and the grafted block-polymer, thereby preventing or hindering Doxy release, as shown in Scheme 2. In contrast, the releases of Doxy from PTBAEMA-b-POEGMA-MSNs with amine in the inner surface at both pH 6 and $\mathrm{pH} 7$ was $\sim 40 \%$. Interestingly, this release rate is $20 \%$ lower than the release rate for PTBAEMA-b-POEGMA-MSNs without amine in the inner surface. This change may result from the covalent binding between the Doxy molecules and the amino group in the inner surface of the material, as shown in Scheme S1. 

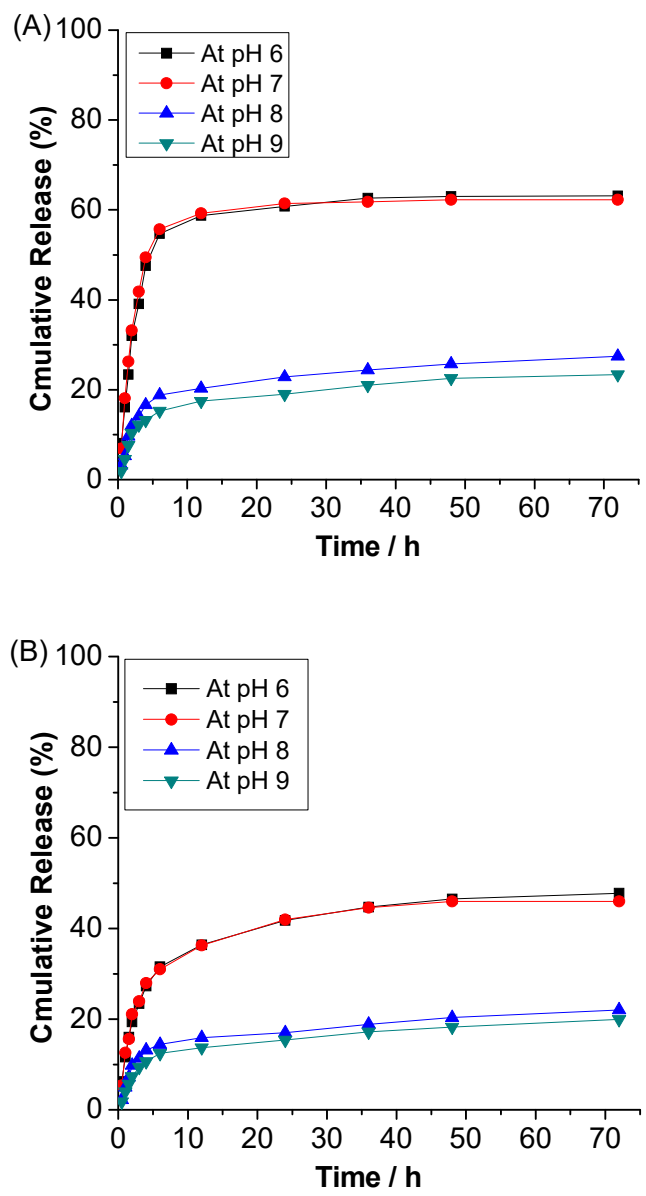

Figure 6. Drug release profiles of Doxy loaded in: (A) PTBAEMA-b-POEGMA-MSNs (without amine in inner surface) and (B) PTBAEMA-b-POEGMA-MSNs (with amine in inner surface) nanocarriers in mild acidic (6.0), neutral (7.0), and basic (8.0 and 9.0) $\mathrm{pH}$ conditions at room temperature.

\section{Conclusions}

In summary, we reported a facile synthesis of well-defined diblock copolymer-grafted on the outer surface of mesoporous silica nanoparticles, i.e., PTBAEMA-b-PEGMEMA-MSNs, via ATRP. Amino-functionalized silane was first attached to the surfaces of MSNs, followed by reaction with BIBB to initiate ATRP, which was then followed by growing PTBAEMA on the nanoparticle surfaces. The retention of the end-group functionality allowed chain extensions from the PTBAEMA-MSNs with PEGMEMA using the AGET ATRP method. The characterizations via TEM, DLS, FT-IR, and TGA confirmed that the PTBAEMA-b-PEGMEMA-MSNs were prepared successfully. DLS was used to investigate the diblock copolymer chain swelling at a $\mathrm{pH}<8$ which arises from the protonation of the secondary amine groups in the PTBAEMA chains, and the expected size decrease in the nanohybrids occurred when the $\mathrm{pH}>8$. Doxy was loaded efficiently into the PTBAEMA-b-PEGMEMA-MSN nanostructures, and the drug was released in a relatively controlled $\mathrm{pH}$-triggered manner.

Supplementary Materials: The following are available online: Figure S1: (A) TEM image of unmodified mesoporous silica nanoparticles. (B) The particle-size distribution of the fabricated nanoparticles, Scheme S1: Illustration the possible interaction between Doxy and amino groups in the MSNs surface.

Author Contributions: K.M.A., M.D.A., B.M.A., and A.M.B. performed the experiments, analyzed the data, wrote the draft paper; A.M.A. and M.S.A. conceived and designed the experiments, revised the paper and provided the overall consulting. All authors have read and agreed to the published version of the manuscript.

Funding: This research received no external funding.

Acknowledgments: This project was supported by King Saud University, Deanship of Scientific Research, College of Science Research Center. 
Conflicts of Interest: The authors declare no conflict of interest.

\section{References}

1. Beck, J.S.; Vartuli, J.; Roth, W.J.; Leonowicz, M.; Kresge, C.; Schmitt, K.; Chu, C.; Olson, D.H.; Sheppard, E.; McCullen, S. A New Family of Mesoporous Molecular Sieves Prepared with Liquid Crystal Templates. J. Am. Chem. Soc. 1992, 114, 10834-10843. [CrossRef]

2. Wu, S.-H.; Mou, C.-Y.; Lin, H.-P. Synthesis of Mesoporous Silica Nanoparticles. Chem. Soc. Rev. 2013, 42, 3862-3875. [CrossRef] [PubMed]

3. Reich, S.-J.; Svidrytski, A.; Höltzel, A.; Florek, J.; Kleitz, F.; Wang, W.; Kübel, C.; Hlushkou, D.; Tallarek, U. Hindered Diffusion in Ordered Mesoporous Silicas: Insights from Pore-Scale Simulations in Physical Reconstructions of SBA-15 and KIT-6 Silica. J. Phys. Chem. C 2018, 122, 12350-12361. [CrossRef]

4. Mal, N.K.; Fujiwara, M.; Tanaka, Y. Photocontrolled Reversible Release of Guest Molecules from Coumarin-Modified Mesoporous Silica. Nature 2003, 421, 350. [CrossRef] [PubMed]

5. Burkett, S.L.; Sims, S.D.; Mann, S. Synthesis of Hybrid Inorganic-organic Mesoporous Silica by Co-Condensation of Siloxane and Organosiloxane Precursors. Chem. Commun. 1996, 11, 1367-1368. [CrossRef]

6. Lu, J.; Liong, M.; Li, Z.; Zink, J.I.; Tamanoi, F. Biocompatibility, Biodistribution, and Drug-Delivery Efficiency of Mesoporous Silica Nanoparticles for Cancer Therapy in Animals. Small 2010, 6, 1794-1805. [CrossRef]

7. Chen, K.-J.; Chen, H.-L.; Tang, C.-C.; Wu, H.-H.; Jan, J.-S. Synthesis of Silica/Polypeptide Hybrid Nanomaterials and Mesoporous Silica by Molecular Replication of Sheet-Like Polypeptide Complexes through Biomimetic Mineralization. J. Colloid Interface Sci. 2019, 542, 243-252. [CrossRef]

8. Tang, F.; Li, L.; Chen, D. Mesoporous Silica Nanoparticles: Synthesis, Biocompatibility and Drug Delivery. Adv. Mater. 2012, 24, 1504-1534. [CrossRef]

9. Slowing, I.I.; Vivero-Escoto, J.L.; Trewyn, B.G.; Lin, V.S.-Y. Mesoporous Silica Nanoparticles: Structural Design and Applications. J. Mater. Chem. 2010, 20, 7924-7937. [CrossRef]

10. Liu, C.; Guo, J.; Yang, W.; Hu, J.; Wang, C.; Fu, S. Magnetic Mesoporous Silica Microspheres with Thermo-Sensitive Polymer Shell for Controlled Drug Release. J. Mater. Chem. 2009, 19, 4764-4770. [CrossRef]

11. Wang, Y.; Yin, M.; Lin, X.; Li, L.; Li, Z.; Ren, X.; Sun, Y. Tailored Synthesis of Polymer-Brush-Grafted Mesoporous Silicas with N-Halamine and Quaternary Ammonium Groups for Antimicrobial Applications. J. Colloid Interface Sci. 2019, 533, 604-611. [CrossRef] [PubMed]

12. Liu, R.; Liao, P.; Liu, J.; Feng, P. Responsive Polymer-Coated Mesoporous Silica as a pH-Sensitive Nanocarrier for Controlled Release. Langmuir 2011, 27, 3095-3099. [CrossRef] [PubMed]

13. Zhang, X.; Yang, P.; Dai, Y.; Ma, P.A.; Li, X.; Cheng, Z.; Hou, Z.; Kang, X.; Li, C.; Lin, J. Multifunctional Up-Converting Nanocomposites with Smart Polymer Brushes Gated Mesopores for Cell Imaging and Thermo/pH Dual-Responsive Drug Controlled Release. Adv. Funct. Mater. 2013, 23, 4067-4078. [CrossRef]

14. Zhang, A.; Jung, K.; Li, A.; Liu, J.; Boyer, C. Recent Advances in Stimuli-Responsive Polymer Systems for Remotely Controlled Drug Release. Prog. Polym. Sci. 2019, 99, 101164. [CrossRef]

15. Wells, C.M.; Harris, M.; Choi, L.; Murali, V.P.; Guerra, F.D.; Jennings, J.A. Stimuli-Responsive Drug Release from Smart Polymers. J. Funct. Biomater. 2019, 10, 34. [CrossRef] [PubMed]

16. Husseman, M.; Malmström, E.E.; McNamara, M.; Mate, M.; Mecerreyes, D.; Benoit, D.G.; Hedrick, J.L.; Mansky, P.; Huang, E.; Russell, T.P. Controlled Synthesis of Polymer Brushes by “Living” Free Radical Polymerization Techniques. Macromolecules 1999, 32, 1424-1431. [CrossRef]

17. Matyjaszewski, K.; Miller, P.J.; Shukla, N.; Immaraporn, B.; Gelman, A.; Luokala, B.B.; Siclovan, T.M.; Kickelbick, G.; Vallant, T.; Hoffmann, H. Polymers at Interfaces: Using Atom Transfer Radical Polymerization in the Controlled Growth of Homopolymers and Block Copolymers from Silicon Surfaces in the Absence of Untethered Sacrificial Initiator. Macromolecules 1999, 32, 8716-8724. [CrossRef]

18. Perruchot, C.; Khan, M.; Kamitsi, A.; Armes, S.V.; Von Werne, T.; Patten, T. Synthesis of Well-Defined, Polymer-Grafted Silica Particles by Aqueous ATRP. Langmuir 2001, 17, 4479-4481. [CrossRef]

19. Zhao, Y.; Perrier, S. Synthesis of Well-Defined Homopolymer and Diblock Copolymer Grafted onto Silica Particles by Z-Supported RAFT Polymerization. Macromolecules 2006, 39, 8603-8608. [CrossRef]

20. Hawker, C.J.; Bosman, A.W.; Harth, E. New Polymer Synthesis by Nitroxide Mediated Living Radical Polymerizations. Chem. Rev. 2001, 101, 3661-3688. [CrossRef] 
21. Matyjaszewski, K.; Xia, J. Atom Transfer Radical Polymerization. Chem. Rev. 2001, 101, 2921-2990. [CrossRef] [PubMed]

22. Schmaljohann, D. Thermo-And pH-Responsive Polymers in Drug Delivery. Adv. Drug Deliv. Rev. 2006, 58, 1655-1670. [CrossRef] [PubMed]

23. Ji, Y.; Lin, X.; Zhang, H.; Wu, Y.; Li, J.; He, Q. Thermoresponsive Polymer Brush Modulation on the Direction of Motion of Phoretically Driven Janus Micromotors. Angew. Chem. Int. Ed. 2019, 58, 4184-4188. [CrossRef] [PubMed]

24. Minko, S. Responsive Polymer Brushes. J. Macromol. Sci. Part C Polym. Rev. 2006, 46, 397-420. [CrossRef]

25. Draper, J.; Luzinov, I.; Minko, S.; Tokarev, I.; Stamm, M. Mixed Polymer Brushes by Sequential Polymer Addition: Anchoring Layer Effect. Langmuir 2004, 20, 4064-4075. [CrossRef] [PubMed]

26. Grest, G.S.; Murat, M. Structure of Grafted Polymeric Brushes in Solvents of Varying Quality: A Molecular Dynamics Study. Macromolecules 1993, 26, 3108-3117. [CrossRef]

27. Dong, R.; Lindau, M.; Ober, C.K. Dissociation Behavior of Weak Polyelectrolyte Brushes on a Planar Surface. Langmuir 2009, 25, 4774-4779. [CrossRef]

28. Treat, N.D.; Ayres, N.; Boyes, S.G.; Brittain, W.J. A Facile Route to Poly (Acrylic Acid) Brushes Using Atom Transfer Radical Polymerization. Macromolecules 2006, 39, 26-29. [CrossRef]

29. Leggett, G.J. Tools for Low-Dimensional Chemistry. Langmuir 2018. [CrossRef]

30. Du, Z.; Sun, X.; Tai, X.; Wang, G.; Liu, X. Synthesis of Hybrid Silica Nanoparticles Grafted with Thermoresponsive Poly (Ethylene Glycol) Methyl Ether Methacrylate Via AGET-ATRP. RSC Adv. 2015, 5, 17194-17201. [CrossRef]

31. Chen, T.; Wu, W.; Xiao, H.; Chen, Y.; Chen, M.; Li, J. Intelligent Drug Delivery System Based on Mesoporous Silica Nanoparticles Coated with an Ultra-pH-Sensitive Gatekeeper and Poly (Ethylene Glycol). ACS Macro Lett. 2015, 5, 55-58. [CrossRef]

32. Alswieleh, A.M.; Cheng, N.; Leggett, G.J.; Armes, S.P. Spatial Control Over Cross-Linking Dictates the pH-Responsive Behavior of Poly (2-(Tert-Butylamino) Ethyl Methacrylate) Brushes. Langmuir 2014, 30, 1391-1400. [CrossRef] [PubMed]

33. Chang, B.; Sha, X.; Guo, J.; Jiao, Y.; Wang, C.; Yang, W. Thermo and pH Dual Responsive, Polymer Shell Coated, Magnetic Mesoporous Silica Nanoparticles for Controlled Drug Release. J. Mater. Chem. 2011, 21, 9239-9247. [CrossRef]

34. Wu, L.; Glebe, U.; Böker, A. Synthesis of Hybrid Silica Nanoparticles Densely Grafted with Thermo and pH Dual-Responsive Brushes Via Surface-Initiated ATRP. Macromolecules 2016, 49, 9586-9596. [CrossRef]

Sample Availability: Samples of the compounds are not available from the authors.

(C) 2020 by the authors. Licensee MDPI, Basel, Switzerland. This article is an open access article distributed under the terms and conditions of the Creative Commons Attribution (CC BY) license (http://creativecommons.org/licenses/by/4.0/). 